Care: Jurnal Ilmiah Ilmu Kesehatan Vol.8, No.3, 2020, hal 447-463

Tersedia online di https://jurnal.unitri.ac.id/index.php/care

ISSN 2527-8487 (online)

ISSN 2089-4503 (cetak)

\title{
PERBANDINGAN INTERPRETASI SKALA NYERI ANTARA NRS-VAS-WBFS OLEH PASIEN PASCA OPERASI ELEKTIF ORTHOPEDI DI RSUD Dr. SOETOMO
}

\author{
Ginong Pratitdya ${ }^{1)}$, Nancy M. Rehatta ${ }^{2)}$, Dedi Susila ${ }^{3)}$ \\ 1),2),3 Program Studi Anestesiologi dan Terapi Intensif \\ Fakultas Kedokteran Universitas Airlangga Surabaya \\ E-mail: Ginongpratidya@gmail.com
}

\begin{abstract}
Health management is still a challenge in health services. An instrument that can cure pain is easy, easy, with accurate interpretation and can be used by every party involved in pain management. The purpose of this study was to analyze the Numeric Rating Scale (NRS), Visual Analogue Scale (VAS), and Wong Baker Faces Scale (WBFS), which can be interpreted well by postoperative care patients. The research method used was an observational analytic study with a cross-sectional study design that analyzed the scale application (NRS, VAS, WBFS) in patients after elective orthopedic surgery at RSUD Dr. Soetomo Surabaya. This study analyzed primary data of postoperative patients which contained socio-demographic characteristics, type of anesthesia given, pain scores and patient interpretation of pain scales through special instruments. The results showed that 102 research subjects were needed. The pain scale interpretation instrument was declared valid and reliable (Cronbach Alpha> 0.60). Mean pain scores from the VAS scale (4.29), NRS (4.82) and WBFS (4.81). No significant difference was obtained NRS scale and WBFS scale (Sig> 0.05). Mean interpretation of pain scale from the VAS scale (13.62), NRS (17.14) and WBFS (21.33). There was a significant difference in the pain score of the $V A S$ scale against the NRS scale, also the WBFS scale (Sig <0.05). There were significant differences between pre and post operations, in clinical parameters of systolic blood pressure, diastolic blood pressure, pulse, and respiratory rate (Sig. <0.05). The conclusion from this study is that NRS, WBFS or VAS all work well in measuring pain. WBFS has the best scale interpretation value.
\end{abstract}

Keywords: Interpretation; pain; NRS; VAS; WBFS.

\begin{abstract}
ABSTRAK
Manajemen nyeri masih menjadi tantangan dalam pelayanan kesehatan. Diperlukan instrumen penilaian nyeri yang obyektif, mudah, dengan interpretasi akurat dan dapat digunakan oleh setiap pihak yang terlibat dalam penanganan nyeri. Tujuan penelitian ini adalah untuk menganalisis penilaian skala nyeri Numeric Rating Scale (NRS), Visual Analogue Scale (VAS), dan Wong Baker Faces Scale (WBFS), yang dapat diinterpretasikan serta dipahami oleh pasien nyeri pasca operasi. Metode penelitian berupa Studi analitik observasional dengan rancangan penelitian secara cross- sectional study yang menganalisis
\end{abstract}

Cara mengutip: Pratitdya, Ginong., Rehatta, Nancy M. \& Susila, Dedi. (2020). Perbandingan Interpretasi Skala Nyeri antara NRSVAS-WBFS oleh Pasien Pasca Operasi Elektif Orthopedi di RSUD Dr. Soetomo. Care:Jurnal Ilmiah Ilmu Kesehatan, 8(3),447-463 
perangkat penilaian skala nyeri (NRS, VAS, WBFS) pada pasien pasca operasi orthopedi elektif di RSUD Dr. Soetomo Surabaya. Penelitian ini menganalisis data primer pasien pasca operasi yang berupa karakteristik sosio-demografi, jenis anestesi yang diberikan, skor nyeri dan interpretasi pasien terhadap skala nyeri melalui instrumen khusus. Hasil penelitian menunjukkan terdapat 102 subyek penelitian. Instrumen interpretasi skala nyeri dinyatakan valid dan reliabel (Cronbach Alpha $>0,60$ ). Mean skor nyeri dari skala VAS $(4,29)$, NRS $(4,82)$ dan WBFS $(4,81)$. Tidak didapatkan perbedaan yang signifikan skala NRS dan skala WBFS (Sig > 0,05). Mean interpretasi skala nyeri dari skala VAS $(13,62)$, NRS $(17,14)$ dan WBFS $(21,33)$. Terdapat perbedaan yang signifikan dari skor nyeri skala VAS terhadap skala NRS, maupun skala WBFS (Sig < 0,05). Terdapat perbedaan yang signifikan antara pre dan post operasi, pada seluruh parameter klinis tekanan darah sistolik, tekanan darah diastolik, nadi, dan respiratory rate (Sig. $<0.05)$. Kesimpulan dari penelitian ini adalah NRS, WBFS atau VAS semuanya bekerja dengan baik dalam mengukur nyeri. WBFS memiliki nilai interpretasi skala yang paling baik.

Kata Kunci: Interpretasi; nyeri; NRS; VAS; WBFS.

\section{PENDAHULUAN}

Manajemen nyeri masih merupakan masalah yang belum terselesaikan pada semua fasilitas pelayanan kesehatan (Evans, 2012). Diperlukan suatu pemeriksaan dan penilaian nyeri yang obyektif, mudah dan dapat digunakan oleh setiap pihak yang terlibat dalam penanganan nyeri dengan hasil yang dapat dipercaya. Menurut International Association for Study of Pain (LASP), nyeri didefinisikan sebagai suatu sensori subyektif dan emosional tidak menyenangkan yang didapat, terkait dengan kerusakan jaringan aktual maupun potensial, atau menggambarkan kondisi terjadinya kerusakan (Treede, 2018).

Tatalaksana nyeri pasca operasi masih jauh dari memuaskan meskipun kualitas dan modalitas penanganan nyeri makin berkembang (Schroeder et al., 2016). Berbagai observasi dan diskusi terhadap pasien yang pernah dilakukan operasi, keluhan nyeri masih menjadi hal yang menakutkan bagi pasien (Glowacki, 2015). Sebuah survey di Amerika Serikat menunjukkan bahwa hanya satu dari empat pasien yang mendapatkan penanganan nyeri pasca operasi secara adekuat, apalagi di negara- negara yang sedang berkembang seperti negara kitaini (Wels D., 2015).

Tata laksana nyeri yang baik dan adekuat akan mempercepat mobilisasi pasca operasi, diet peroral bisa lebih optimal dan stress pembedahan bisa diminimalisir sehingga masa pemulihan bisa lebih cepat serta pasien menjadi puas (Brennan, 2011). Tingkat kepatuhan dan pemahaman dalam menilai serta 
menjalankan panduan nyeri baik oleh dokter non anestesi maupun tenagamedislainnya misalnya perawat juga menjadi bagian penting dalam pelayanan manajemen nyeri (Fitzgerald, Tripp, \& Halksworth-Smith, 2017). Sebuah penelitian oleh (Kusuma Sari, 2016) mengenai Implementasi NIPS (Neonatal Infant Pain Scale) menyebutkan bahwa tingkat kepatuhan tatalaksana nyeri sebelum tindakan invasif pada neonatus meningkat setelah diberlakukan protokol yang ketat, sosialisasi dan penyuluhan (Kusuma Sari, 2016).

Berkomunikasi dengan pasien yang sedang mengalami nyeri juga dibutuhkan suatu cara khusus, agar petugas medis dan pasien dapat berkomunikasi dengan baik. Terdapat berbagai skala penilaian nyeri yang digunakan, diantaranya uni dimensional (untuk mengukur intensitas nyeri akut) dan skala multi dimensional (untuk mengukur intensitas nyeri kronis) (Ali \& Lewis, 2015). Skala Uni dimensional nyeri akut yang banyak digunakan diantaranya Visual Analog Scale (VAS), Verbal Rating Scale, Numericrating Scale, dan Wong Baker Pain Rating Scale. Sedangkan skala multidimensional seperti Mc Gill Pain Questionnaire (MPQ), MemorialPain Assessment Card, dan sebagainya. Pada kelompok pasien neonatus digunakan skala Neonatal Infant PainScale (NIPS), untuk pasien anak $>3$ tahun yang tidak dapat menggambarkan intensitas nyerinya dengan angka, digunakan Wong Baker FACES Pain Scale atau Face-LegsActivity-Cry-Consolability $\quad$ (FLACCS), sedangkan pada anak $>8$ tahun dapat menggunakan VAS (Wall\&Melzack's., n.d.).

Menegakkan keluhan nyeri pada pasien merupakan langkah yang membutuhkan kehati-hatian untuk kelak dapat memberikan tatalaksana nyeri dengan baik. Anderson, dkek menemukan ada jarak antara penilaian nyeri dengan tatalaksana yang diberikan oleh tenaga medis, harus ada standar yang menjadi acuan dalam menilai nyeri. Joint Commisission on Accreditation of Healthcare Organization membuat standar khusus yang bisa digunakan sebagai acuan untuk menilai nyeri, dimana standar penilaian nyeri tersebut dapat digunakan disemua departemen. Standar tersebut, yaitu:Numeric Rating Scale (NRS), Visual Analog Scale (VAS), dan Faces Scale yang dimodifikasi oleh Wong-Baker (WBFS) (Angeline, Allan, Ana, \& Kenneth, 2015)

Suatu keadaan nyeri atau sakit dapat membuat orang terganggu untuk 
menjalankan aktifitasnya dan mengharuskan seseorang untuk beristirahat, sehingga semua tugas-tugas wajibnya tertunda. Tidak hanya sakit fisik, seseorang atau pasien juga dapat pula terganggu psikologisnya. Keadaan demikian membuat seseorang tersebut terganggu dalam menanggapi suatu situasi, apalagi harus sampai mengambil keputusan.

Program manajemen pengelolaan nyeri bertujuan untuk memberikan pelayanan sesuai dengan prosedur dan untuk menghindari dampak akibat tatalaksana yang tidak adekuat. Salah satu hal yang cukup disorot adalah mengenai alat skrining dan penilaian nyeri yang bervariasi serta perbedaan hasil penilaian nyeri yang berbeda di antara pemberi pelayanan kesehatan di fasilitas rumah sakit. Selain itu, dengan latar belakang pendidikan serta data demografi pasien yang berbeda pula maka tingkat pemahaman dan pengetahuan mengenai cara penilaian nyeri menggunakan alat skrining nyeri dapat berbeda juga.

Penelitian yang dilakukan di Filipina oleh Juneth, dke pada tahun 2015, Numeric Rating Scale (NRS) merupakan skala yang valid digunakan pada pasien Reumatik Artritis, dan Faces Scale sebagai alternative apabila pasien tidak paham akan angkaangka.(Gallagher, Bijur, Latimer, \& Silver, 2002). Unit Gawat Darurat salah satu Rumah Sakit di New York, Amerika Serikat, tingkat nyeri pada pasien akut abdomen dapat dinilai dalam waktu 1 menit dengan Visual Analog Scale (VAS), dengan populasi perempuan 61\%, lakilaki 39\%, usia rata-rata 40 tahun, dan dengan komunikasi berbahasa Inggris dan Perancis. (Magbagbeola, 2001). Tahun 2001 di Negeria, Magbagbeola, dkk mencoba mengkomparasi antara Visual Analog Scale (VAS) dan Verba Rating Scale (VRS) versi bahasa Inggris dengan bahasa Yoruba (Nigeria), dan ternyata hasilnya sangat signifikan, bahasa Yoruba lebih mudah dipahami oleh pasien-pasien di Nigeria (Merskey \& Bogduk, 1994). Dari segala aspek dan latar belakang itulah, maka pada penelitian ini peneliti ingin mengetahui perangkat penilaian nyeri manakah yang mudah diinterpretasikan oleh pasien-pasien yang dirawat pasca operasi elektif orthopedi, sehingga dapat digunakan sebagai standar pelayanan manajemen nyeri dalam menilai nyeri di RSUD Dr. Soetomo.

\section{METODE PENELITIAN}

Penelitian ini merupakan penelitian analisis observasional dengan rancangan penelitian secara cross-sectional study yang 
menganalisis perangkat penilaian skala nyeri (NRS, VAS, WBFS) pada pasien nyeri pasca operasi 2 jam setelah efek obat bius selesai. Penelitian ini menganalisis data yang berasal dari survei/kuesioner pasien nyeri pasca operasi di ruang perawatan Bedah RSUD Dr. Soetomo Surabaya. Pada penelitian ini juga dilakukan analisa data primer pasien pasca operasi yang berupa karakteristik sosio-demografi (umur, jenis kelamin dan tingkat pendidikan), jenis anestesi yang diberikan. Penelitian ini dimulai pada bulan September sampai dengan Oktober tahun 2019 yang dilakukan di ruang perawatan Bedah RSUD Dr. Soetomo Surabaya. Populasi penelitian adalah semua pasien yang menjalani operasi elektif orthopedi di RSUD Dr. Soetomo dan mendapatkan pelayanan tatalaksana nyeri akut pasca operasi. Sampel adalah pasien yang menjalani operasi elektif dan telah mendapatkan pelayanan tatalaksana nyeri akut pasca operasi di lingkungan RSUD Dr. Soetomo yang memenuhi kriteria inklusi dan eksklusi, dengan total sampling yang diambil dari masingmasing ruang perawatan Bedah dalam periode waktu selama bulan September Oktober. Ketepatan pengujian suatu hipotesis tentang hubungan penelitian sangat tergantung pada kualitas data yang dipakai dalam pengujian tersebut. Untuk mendapatkan alat pengukur yang relatif konsisten, maka perlu uji validitas dan uji reliabilitas. Analisis data interpretasi skala nyeri antara NRS-VAS-WBFS oleh pasien pasca operasi elektif dalam penelitian ini menggunakan program komputer SPSS. pengambilan data dilakukan melalui metode wawancara.

\section{HASIL}

Subyek penelitian merupakan data dari pasien operasi elektif orthopedi yang menjalani tindakan di Gedung Bedah Pusat Terpadu (GBPT) RSUD Dr. Soetomo Surabaya pada bulan September - Oktober 2019, dimulai dengan pemilahan subyek berdasarkan kriteria inklusi dan eksklusi. Data dikumpulkan melalui lembar pengumpul data khusus, didapatkan sampel sebanyak 102 pasien. Penelitian ini menganalisis perangkat penilaian skala nyeri (NRS, VAS, WBFS) pada pasien nyeri pasca operasi 2 jam setelah efek obat bius selesai.

Derajat nyeri pasca operasi adalah derajat nyeri yang dialami oleh pasien pada akhir periode masa kerja obat bius pasca operasi, skor nyeri akan dinilai menggunakan 3 skala nyeri Numerical Rating Scale (NRS), Visual Analog Scale (VAS) dan Wong-Baker Faces Scale (WBFS). Dilakukan oleh pasien yang didampingi 
oleh peneliti, dengan cara mengisi lembaran questioner.

Derajat nyeri diukur dengan skor, dan pada penelitian ini ditemukan bahwa mean skor nyeri dari subyek penelitian menggunakan skala $\operatorname{VAS}(4,29)$, lebih rendah daripada skala NRS $(4,82)$ dan
$\operatorname{WBFS}(4,81)$. Pada hasil uji komparasi terdapat perbedaan yang signifikan dari skor nyeri skala $V A S$ terhadap skala NRS, maupun skala WBFS (Sig < 0,05). Sedangkan pada uji komparasi antara skor nyeri skala NRS dan skala WBFS tidak didapatkan perbedaan yang signifikan (Sig $>0,05)$.

Tabel 1. Karakteristik subyek penelitian

\begin{tabular}{|c|c|c|c|}
\hline & & $\mathrm{N}$ & $(\%)$ \\
\hline \multirow[t]{2}{*}{ Jenis Kelamin } & Laki Laki & 73 & 71,57 \\
\hline & Perempuan & 29 & 28,43 \\
\hline \multirow[t]{3}{*}{ Usia } & Dewasa muda (18-35 tahun) & 43 & 42,15 \\
\hline & Dewasa tua (36-55 tahun) & 46 & 45,09 \\
\hline & Lanjut usia (lebih 55 tahun) & 13 & 12,76 \\
\hline \multirow[t]{5}{*}{ Pendidikan } & Tidak Sekolah & 1 & 0,98 \\
\hline & SD/Sederajat & 7 & 6,86 \\
\hline & SMP/Sederajat & 3 & 2,94 \\
\hline & SMA/Sederajat & 74 & 72,55 \\
\hline & Perguruan Tinggi & 17 & 16,67 \\
\hline \multirow[t]{5}{*}{ Pekerjaan } & Tidak Bekerja & 23 & 22,55 \\
\hline & Pegawai Negeri & 2 & 1,96 \\
\hline & Pegawai Swasta & 48 & 47,06 \\
\hline & Wirausaha & 28 & 27,45 \\
\hline & Pensiun & 1 & 0,98 \\
\hline \multirow[t]{3}{*}{ Operasi } & 1 kali & 58 & 56,86 \\
\hline & 2 kali & 42 & 41,18 \\
\hline & $>2$ kali & 2 & 1,96 \\
\hline \multirow[t]{3}{*}{ Bius } & 1 kali & 58 & 56,86 \\
\hline & 2 kali & 42 & 41,18 \\
\hline & $>2$ kali & 2 & 1,96 \\
\hline \multirow[t]{8}{*}{ Jenis Anestesi } & CSEA & 21 & 20,59 \\
\hline & GA Epidural & 23 & 22,55 \\
\hline & GA Intubasi & 32 & 31,37 \\
\hline & GA LMA & 7 & 6,86 \\
\hline & GA Masker & 11 & 10,78 \\
\hline & GA TIVA & 1 & 0,98 \\
\hline & PNB & 3 & 2,94 \\
\hline & $\mathrm{SAB}$ & 4 & 3,92 \\
\hline \multirow[t]{3}{*}{ PS ASA } & 1 & 13 & 12,75 \\
\hline & 2 & 74 & 72,55 \\
\hline & 3 & 15 & 14,71 \\
\hline
\end{tabular}

Interpretasi pasien adalah proses antara dokter/perawat dan pasien dengan komunikasi melalui lisan atau gerakan ataupun tanpa alat bantu. Istilah 
interpretasi sendiri dapat merujuk pada proses penafsiran yang sedang berlangsung atau hasilnya. Penafsiran itu dapat berupa lisan, tulisan, gambar, matematika, atau berbagai bentuk bahasa lainnya.

Interpretasi pasien terhadap skala nyeri diukur dengan lembar pengumpulan data khusus, dengan 6 item tiap instrumen dengan nilai maksimal skala Likert 4. Pada penelitian ini ditemukan bahwa mean interpretasi skala nyeri dari subyek penelitian menggunakan terkait skala $V A S(13,62)$, lebih rendah daripada skala NRS $(17,14)$ dan $W B F S(21,33)$. Pada hasil uji komparasi terdapat perbedaan yang signifikan dari skor nyeri skala $V A S$ terhadap skala NRS, maupun skala WBFS (Sig < 0,05). Sedangkan pada uji komparasi antara skor nyeri skala NRS dan skala WBFS tidak didapatkan perbedaan yang signifikan (Sig >0,05).

Pada instrumen interpretasi skala nyeri, terdapat masing-masing 6 pertanyaan yang terdiri dari 3 pertanyaan positif, dan 3 pertanyaan negatif. Ketepatan pengujian suatu hipotesis tentang hubungan penelitian sangat tergantung pada kualitas data yang dipakai dalam pengujian tersebut. Untuk mendapatkan alat pengukur yang relatif konsisten, maka perlu uji validitas dan uji reliabilitas. Penelitian ini melakukan uji validitas dengan face validity, Kemudian dilakukan uji korelasi product moment antara skor item dengan skor total. Uji korelasi ini bertujuan untuk menguji tiap butir pertanyaan yang dapat mengungkap faktor yang akan diukur atau konsistensi tiap item alat ukur dalam mengukur suatu faktor. Nilai korelasi yang diperoleh (nilai korelasi per item dengan total item yang diperoleh setelah dikorelasikan secara statistik per individu) lalu dibandingkan dengan Tabel nilai korelasi (r) product moment untuk mengetahui nilai korelasi yang diperoleh signifikan atau tidak. Jika indeks nilai yang diperoleh dari perhitungan tersebut memiliki nilai yang lebih besar dari nilai Tabel korelasi, maka item itu dinyatakan valid demikian juga sebaliknya. Pada hasil peneleitian didapatkan seluruh item pada instrumen dinyatakan valid ( $r$ hitung $>\mathrm{r}$ tabel).

Reliabilitas dapat diartikan sebagai suatu petunjuk akurasi alat ukur yang digunakan dapat dipercaya atau dapat diandalkan. Dengan kata lain, akurasi alat ukur yang digunakan dapat memberi hasil yang relatif tidak berbeda jika dilakukan pengukuran ulang. Pada hasil analisis didapatkan masing-masing instrumen yang mengukur interpretasi subyek 
penelitian dinyatakan reliabel dengan nilai Cronbach Alpha > 0, 60.

Pada penelitian ini dilakukan pengukuran skala nyeri pasca operasi 2 jam setelah setelah efek obat bius habis. Pada penelitian ini dilakukan pengukuran interpretasi pasien terhadap skala nyeri pasca operasi 2 jam setelah setelah efek obat bius habis. Instrumen pengukuran skala nyeri yang digunakan adalah Lembar Pengumpulan Data Khusus terkait interpretasi skala Visual Analogue Scale (VAS), Numeric Rating Scale (NRS), dan Wong Baker Faces Scale (WBFS) Pada seluruh komponen demografis tidak didapatkan adanya perbedaan signifikan pada interpretasi nyeri, baik terkait skala $V A S$, NRS, maupun WBFS; nilai Sig $>0,05$.

Tabel 2. Hasil Uji Validitas dan Uji Reliabilitas Instrumen yang Mengukur Interpretasi Subyek Penelitian

\begin{tabular}{llrc} 
& \multicolumn{1}{c}{$\mathrm{R}$} & Cronbach Alpha \\
\hline VAS & VAS Paham & 0,689 & \\
& VAS cepat & 0,619 & \\
& VAS posisi & 0,607 & 0,684 \\
& VAS sulit & 0,674 & \\
& VAS Berpikir & 0,537 & \\
& VAS tidak sesuai Nyeri & 0,641 & \\
\hline NRS & NRS Paham & 0,653 & \\
& NRS cepat & 0,431 & \\
& NRS posisi & 0,320 & \\
& NRS sulit & 0,653 & \\
& NRS Berpikir & 0,326 & \\
& NRS tidak sesuai Nyeri & 0,206 & \\
\hline WBFS & WBFS Paham & 0,842 & \\
& WBFS cepat & 0,881 & \\
& WBFS posisi & 0,329 & \\
& WBFS sulit & 0,318 & \\
& WBFS Berpikir & 0,318 & \\
& WBFS tidak sesuai Nyeri & 0,332 & \\
\end{tabular}

Pada tabel 3 menunjukan berapa banyak pasien yang memilih skala yang menurut mereka mudah dipahami, dan berdasarkan skor Lickert yang ada di Kuesioner/ Lembar Pengumpulan Data.

Berdasarkan jawaban pertanyaan positif Tabel 3. Uji komparasi interpretasi skala nyeri berdasarkan demografi dan negatif yang terdapat pada Kuesioner. skala $V A S$ memiliki skor Lickert sangat rendah, dan saat dihitung dengan statistik nilainya nol di tabel. Sehingga dikelompokkan berdasarkan data demograf, tanpa dicantumkan skala $V A S$. 


\begin{tabular}{|c|c|c|c|c|c|c|c|c|c|}
\hline & & \multicolumn{2}{|c|}{ WBFS } & \multicolumn{2}{|c|}{ NRS } & \multicolumn{2}{|c|}{$\begin{array}{c}\text { WBFS \& } \\
\text { NRS }\end{array}$} & \multirow{2}{*}{ Total } & \multirow{2}{*}{$P$} \\
\hline & & $\mathrm{n}$ & $\%$ & n & $\%$ & $\mathbf{N}$ & $\%$ & & \\
\hline \multirow[t]{2}{*}{ Jenis Kelamin } & Laki Laki & 67 & $91,8 \%$ & 4 & $5,5 \%$ & 2 & $2,7 \%$ & 73 & \multirow{2}{*}{0,601} \\
\hline & Perempuan & 28 & $96,6 \%$ & 1 & $3,4 \%$ & 0 & $0,0 \%$ & 29 & \\
\hline \multirow[t]{5}{*}{ Pendidikan } & Tidak Sekolah & 1 & $100,0 \%$ & 0 & $0,0 \%$ & 0 & $0,0 \%$ & 1 & \multirow{5}{*}{0,887} \\
\hline & $\mathrm{SD} /$ Sederajat & 7 & $100,0 \%$ & 0 & $0,0 \%$ & 0 & $0,0 \%$ & 7 & \\
\hline & $\mathrm{SMP} /$ Sederajat & 3 & $100,0 \%$ & 0 & $0,0 \%$ & 0 & $0,0 \%$ & 3 & \\
\hline & SMA/Sederajat & 68 & $91,9 \%$ & 5 & $6,8 \%$ & 1 & $1,4 \%$ & 74 & \\
\hline & Perguruan Tinggi & 16 & $94,1 \%$ & 0 & $0,0 \%$ & 1 & $5,9 \%$ & 17 & \\
\hline \multirow[t]{5}{*}{ Pekerjaan } & Tidak Bekerja & 23 & $100,0 \%$ & 0 & $0,0 \%$ & 0 & $0,0 \%$ & 23 & \multirow{5}{*}{0,84} \\
\hline & Pegawai Negeri & 2 & $100,0 \%$ & 0 & $0,0 \%$ & 0 & $0,0 \%$ & 2 & \\
\hline & Pegawai Swasta & 43 & $89,6 \%$ & 3 & $6,3 \%$ & 2 & $4,2 \%$ & 48 & \\
\hline & Wirausaha & 26 & $92,9 \%$ & 2 & $7,1 \%$ & 0 & $0,0 \%$ & 28 & \\
\hline & Pensiun & 1 & $100,0 \%$ & 0 & $0,0 \%$ & 0 & $0,0 \%$ & 1 & \\
\hline \multirow[t]{3}{*}{ Operasi } & 1 kali & 53 & $91,4 \%$ & 4 & $6,9 \%$ & 1 & $1,7 \%$ & 58 & \multirow{3}{*}{0,869} \\
\hline & 2 kali & 40 & $95,2 \%$ & 1 & $2,4 \%$ & 1 & $2,4 \%$ & 42 & \\
\hline & $>2$ kali & 2 & $100,0 \%$ & 0 & $0,0 \%$ & 0 & $0,0 \%$ & 2 & \\
\hline \multirow[t]{3}{*}{ Bius } & 1 kali & 53 & $91,4 \%$ & 4 & $6,9 \%$ & 1 & $1,7 \%$ & 58 & \multirow{3}{*}{0,869} \\
\hline & 2 kali & 40 & $95,2 \%$ & 1 & $2,4 \%$ & 1 & $2,4 \%$ & 42 & \\
\hline & $>2$ kali & 2 & $100,0 \%$ & 0 & $0,0 \%$ & 0 & $0,0 \%$ & 2 & \\
\hline \multirow[t]{8}{*}{ Jenis Anestesi } & CSEA & 21 & $100,0 \%$ & 0 & $0,0 \%$ & 0 & $0,0 \%$ & 21 & \multirow{8}{*}{0,361} \\
\hline & GA Epidural & 21 & $91,3 \%$ & 2 & $8,7 \%$ & 0 & $0,0 \%$ & 23 & \\
\hline & GA Intubasi & 29 & $90,6 \%$ & 2 & $6,3 \%$ & 1 & $3,1 \%$ & 32 & \\
\hline & GA LMA & 6 & $85,7 \%$ & 0 & $0,0 \%$ & 1 & $14,3 \%$ & 7 & \\
\hline & GA Masker & 11 & $100,0 \%$ & 0 & $0,0 \%$ & 0 & $0,0 \%$ & 11 & \\
\hline & GA TIVA & 1 & $100,0 \%$ & 0 & $0,0 \%$ & 0 & $0,0 \%$ & 1 & \\
\hline & PNB & 2 & $66,7 \%$ & 1 & $33,3 \%$ & 0 & $0,0 \%$ & 3 & \\
\hline & $\mathrm{SAB}$ & 4 & $100,0 \%$ & 0 & $0,0 \%$ & 0 & $0,0 \%$ & 4 & \\
\hline \multirow[t]{3}{*}{ PS ASA } & 1 & 13 & $100,0 \%$ & 0 & $0,0 \%$ & 0 & $0,0 \%$ & 13 & \multirow{3}{*}{0,808} \\
\hline & 2 & 68 & $91,9 \%$ & 4 & $5,4 \%$ & 2 & $2,7 \%$ & 74 & \\
\hline & 3 & 14 & $93,3 \%$ & 1 & $6,7 \%$ & 0 & $0,0 \%$ & 15 & \\
\hline
\end{tabular}

Pengukuran parameter klinis juga dilakukan pada subyek penelitian, dengan mengukur tanda-tanda vital pasien (tekanan darah sistol (TDS), tekanan darah diastol (TDD), nadi, dan respiratory rate $(R R)$ ) sebelum dan sesudah dilakukan tindakan operasi elektif orthopaedi.

Tabel 4. Parameter klinis subyekpenelitian 


\begin{tabular}{lccc} 
& Mean & Std. Deviation & Sig \\
\hline TD Sistol Pre Operasi & 121,99 & 11,932 & \multirow{2}{*}{0,000} \\
TDSistol Post Operasi & 129,59 & 9,909 & 0,000 \\
\hline TD Diastol Pre Operasi & 75,11 & 6,623 & \multirow{2}{*}{0,000} \\
TD Diastol Post Operasi & 78,25 & 6,809 & \\
\hline Nadi Pre Operasi & 85,32 & 9,600 & 0,000 \\
Nadi Post Operasi & 94,59 & 8,308 & \\
\hline RR Pre Operasi & 18,19 & 1,069 &, 968 \\
RR Post Operasi & 19,88 &,
\end{tabular}

Pada penelitian ini didapatkan seluruh parameter klinis pre dan post operasi orthopaedi elektif menunjukkan adanya peningkatan mean. Dengan analisis menggunakan Wilcoxon, didapatkan perbedaan yang signifikan antara pre dan post operasi, pada seluruh parameter klinis tekanan darah sistolik (TDS), tekanan darah diastolik (TDS), ndi, dan respiratory rate (RR) dengan Sig. $<0.05$.

80.00

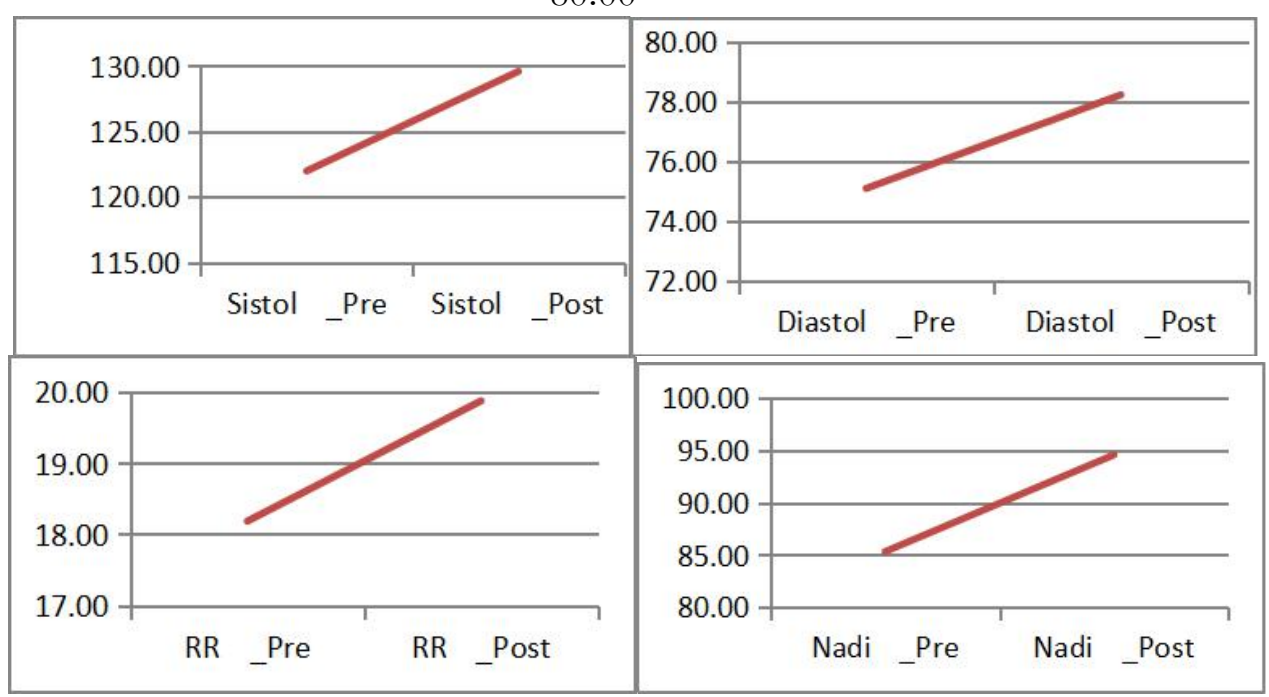

Gambar 1. Peningkatan mean pada parameter klinis pre dan post operasi

\section{PEMBAHASAN}

Tingakat nyeri merupakan dimensi yang paling relevan secara klinis yang secara independen terkait penyakit yang mendasarinya. Pentingnya domain ini, kemudian ditekankan dalam banyak penelitian. Menurut survei para ahli, konferensi, dan konsensus, intensitas nyeri harus dinilai oleh skala unidimensional berdasarkan laporan diri (self-report) pasien. (Von Korff, Jensen, \& Karoly, 2000) Penelitian ini menunjukkan bahwa intensitas nyeri diukur oleh berbagai skala unidimensional, instrumen pengukuran skala nyeri yang digunakan adalah Visual Analogue Scale (VAS), 
Numeric Rating Scale (NRS), dan Wong Baker Faces Scale (WBFS). Perbedaannya kemudian diungkapkan oleh jumlah pilihan dan respons dari subyek penelitian.

Subyek penelitian merupakan data dari pasien operasi elektif orthopedi yang menjalani tindakan di Gedung Bedah Pusat Terpadu (GBPT) RSUD dr. Soetomo Surabaya pada bulan September - Oktober 2019. Pada penelitian ini dilakukan analisis data primer pasien pasca operasi yang berupa karakteristik sosio-demografi (umur, jenis kelamin dan tingkat pendidikan), frekuensi operasi, jenis anestesi yang diberikan, hingga physical status ASA pasien.

Pada penelitian ini didapatkan karakteristik subyek penelitian, dengan jenis kelamin yang berbeda antara lakilaki sejumlah 73 orang, dan perempuan sejumlah 29 orang. Sebagian besar dari subyek penelitian barusia usia dewasa tua (36-55 tahun) dengan persentase 45.09\%. Tingkat pendidikan formal dari subyek penelitian sebagian besar berada pada tingkat Sekolah Menengah Atas (SMA), yakni sebesar 72,55\%, sebagian besar subyek penelitian berstatus pegawai swasta, yakni sebesar 47,06\%. Pada seluruh komponen demografis tidak didapatkan adanya perbedaan signifikan pada skor nyeri, baik skala $V A S$, NRS, maupun WBFS; Sig $>0,05$. Hasil penelitian ini berbeda dengan beberapa studi lain yang serupa. (Avery, 2010)menyatakan bahwa demografi pasien seperti usia dan etnis telah terbukti mempengaruhi bagaimana mereka menilai rasa nyeri. Penelitian oleh(Alghadir, Anwer, Iqbal, \& Iqbal, 2018), menyatakan $V A S$, dan NRS secara signifikan terkait dengan variabel demografis (usia, BMI, jenis kelamin), dengan koefisien korelasi yang tinggi $V A S$, dan NRS, masing-masing adalah 0,97 dan 0,95 .

Sebagian besar subyek baru pertama kali menjalani operasi dan pembiusan, yakni sebesar 56,86\% (58 orang). Tindakan pembiusan yang dilakukan yaitu general ataupun regional. Tindakan pembiusan yang paling banyak adalah General Anesthesia sebanyak 32 subyek penelitian $(31,37 \%)$. Sebagian besar subyek penelitian diklasifikasikan dengan Physical Status American Society of Anesthesiologists (PS ASA) 2, yakni sebesar 72,55\% (74 orang). Pada penelitian ini tidak didapatkan hubungan antara jenis atau metode anestesi terhadap tingkat nyeri. Temuan ini sejalan dengan studi oleh (Naghibi, Saryazdi, Kashefi, \& Rohani, 2013)yang menyatakan tidak ada 
perbedaan signifikan skala $V A S$ pada setting pre-operatif dan 6 jam pascaoperasi.

Derajat nyeri pasca operasi adalah derajat nyeri yang dialami oleh pasien pada akhir periode masa kerja obat bius pasca operasi, skor nyeri akan dinilai menggunakan 3 skala nyeri Numerical Rating Scale (NRS), Visual Analog Scale (VAS) dan Wong-Baker Faces Scale (WBFS). Dilakukan oleh pasien yang didampingi oleh peneliti, dengan cara mengisi lembaran keuesioner. Derajat nyeri diukur dengan skor, dan pada penelitian ini ditemukan bahwa mean skor nyeri dari subyek penelitian menggunakan skala $V A S(4,29)$, lebih rendah daripada skala NRS (4,82) dan WBFS (4,81). Hasil penelitian ini bertolak belakang dengan studi lain yang serupa, dimana kecenderungan terhadap skor NRS yang lebih tinggi ketika pasien memiliki skor nyeri rata-rata yang rendah, sedangkan skor tampak sama antar instrumen skala nyeri ketika pasien memiliki skor rata-rata tinggi (Kjeldsen, Klausen, \& Rosenberg, 2016).

Hasil uji komparasi skor nyeri skala $V A S$ terhadap skala NRS, maupun skala WBFS didapatkan perbedaan signifikan (Sig < 0,05). Sedangkan pada uji komparasi antara skor nyeri skala NRS dan skala
WBFS tidak didapatkan perbedaan yang signifikan (Sig > 0,05). Temuan ini sedikit berbeda dengan penelitian dari (Thong, Jensen, Miró, \& Tan, 2018)yang menyatakan skala NRS, VAS, sangat terkait satu sama lain, mendukung validitas instrumen tersebut sebagai ukuran intensitas nyeri. $V A S$ tampaknya paling mirip dengan NRS dan kurang dipengaruhi oleh faktor intensitas nonnyeri lain. Penelitian oleh (Alice, 2012) pada total 60 pasien di China yang diukur nyeri rata-rata selama satu minggu terakhir, menunjukkan koefisien korelasi Spearman (@) rank untuk NRS dan VAS adalah 0,775 ( $\mathrm{p}<0,001)$. $\varrho$ adalah 0,598 ( $\mathrm{p}$ $<0,001)$ untuk WBFS dan NRS sedangkan untuk WBFS dan $V A S$ adalah 0,511 ( $\mathrm{p}<0,001)$, sehingga ketiga instrumen ini memiliki keakuratan yang baik, serta korelasi yang kuat antar instrumennya dalam mengukur tingkat nyeri pada pasien.

Interpretasi pasien adalah proses komunikasi melalui lisan atau gerakan antara dokter/perawat dan pasien dengan ataupun tanpa alat bantu. Istilah interpretasi sendiri dapat merujuk pada proses penafsiran yang sedang berlangsung atau hasilnya. Penafsiran itu dapat berupa lisan, tulisan, gambar, matematika, atau berbagai bentuk bahasa 
lainnya. Interpretasi pasien terhadap skala nyeri diukur dengan lembar pengumpulan data khusus, dengan 6 item tiap instrumen dengan nilai maksimal skala Likert 4. Pada penelitian ini ditemukan bahwa mean interpretasi skala nyeri dari subyek penelitian menggunakan terkait skala $V A S(13,62)$, lebih rendah daripada skala NRS $(17,14)$ dan $\operatorname{WBFS}(21,33)$. Pada hasil uji komparasi terdapat perbedaan yang signifikan dari skor nyeri skala $V A S$ terhadap skala NRS, maupun skala WBFS (Sig < 0,05). Sedangkan pada uji komparasi antara skor nyeri skala NRS dan skala WBFS tidak didapatkan perbedaan yang signifikan (Sig $>0,05)$. Dari ketiga interpretasi skala nyeri nyeri yang diberikan kepada subyek penelitian, tabel ini menunjukan berapa banyak pasien yang memilih skala yang menurut mereka mudah dipahami, dan berdasarkan skor Lickert yang ada di Kuesioner/ Lembar Pengumpulan Data. Berdasarkan jawaban pertanyaan positif dan negatif yang terdapat pada Kuesioner, skala $V A S$ memiliki skor Lickert sangat rendah, dan saat dihitung dengan statistik nilainya nol di tabel. Sehingga dikelompokkan berdasarkan data demografi, tanpa dicantumkan skala $V A S$.

Sebagian besar skala unidimensional berkinerja cukup baik di semua studi.
Namun secara keseluruhan, pemahaman yang lebih baik dilaporkan cenderung pada NRS relatif terhadap VAS. Skala $V A S$ tampaknya lebih rumit dengan tingkat kesalahan yang lebih tinggi, terutama pada orang lanjut usia atau gangguan kognitif, seperti yang telah dilaporkan pada studi sebelumnya. (Hjermstad et al., 2011)

(Taylor \& Herr, 2003), melakukan penelitian untuk mengidentifikasi yang manakah dari tiga skala pengukuran intensitas nyeri yang paling tepat dan efektif untuk pasien rawat inap. Sampel pada penelitian tersebut terdiri atas 267 pasien, dimana 31\% subyek berusia lebih tua dari 60 tahun. Komposisi minoritas sampel tidak dilaporkan. Tiga skala digunakan, termasuk $V A S$, NRS, dan Wong Baker Faces Scale (WBFS). Pasien menilai nyeri menggunakan semua skala dan kemudian menjawab pertanyaan tentang kemudahan penggunaan dan membantu mereka dalam menentukan skala nyeri, hasil menunjukkan bahwa subyek penelitian menentukan preferensi pada WBFS (48,6\%), diikuti oleh NRS $(35,3 \%)$, dan $V A S(16,1 \%)$.

Hasil penelitian lain yang membandingkan mekanisme NRS dan $V A S$, didapatkan NRS lebih cepat dan 
mudah dipahami. VAS lebih memakan waktu. Instruksi tentang cara menggunakan VAS secara keseluruhan lebih sulit untuk dipahami. Tidak ada korelasi yang signifikan secara statistik antara NRS dan VAS. NRS dan VAS keduanya mengukur skala nyeri yang dapat saling dipertukarkan satu sama lain. Dengan $\mathrm{p}=0,000$, tidak ada kecenderungan skor $V A S$ meningkat atau menurun karena skor NRS meningkat dan sebaliknya. (Avery, 2010)

Pasien dalam penelitian lain yang lebih memilih NRS menjelaskan bahwa mereka merasa itu adalah cara yang lebih akurat. menyatakan level rasa nyeri sebagai nilai numerik dan merasa lebih aman dalam memberikan tingkat rasa nyeri yang dialami pasien secara klinis kepada dokter, sebagai sarana memvisualisasikan sensasi. (Kjeldsen et al., 2016)

Pengukuran parameter klinis juga dilakukan pada subyek penelitian, dengan mengukur tanda-tanda vital pasien, seperti, tekanan darah sistol (TDS), tekanan darah diastol (TDD), nadi, dan respiratory rate $(R R)$ sebelum dan sesudah dilakukan tindakan operasi elektif orthopaedi. Pada penelitian ini didapatkan seluruh parameter klinis pre dan post operasi orthopaedi elektif menunjukkan adanya peningkatan mean. Dengan analisis menggunakan Wilcoxon, didapatkan perbedaan yang signifikan antara pre dan post operasi, pada seluruh parameter klinis tekanan darah sistolik (TDS), tekanan darah diastolik (TDS), nadi, dan respiratory rate ( $\mathrm{RR})$ dengan Sig. $<$ 0.05. Hasil penelitian yang sama ditunjukkan oleh (Chiang, Huang, Lin, Chan, \& Chia, 2019), yang menyatakan adanya hubungan tingkat nyeri pasca operasi dengan tekanan darah sistol maupun diastol. Sebuah systematic review oleh (Jafari, Courtois, Van den Bergh, Vlaeyen, \& Van Diest, 2017), menunjukkan bahwa tingkat nyeri berhubungan dengan frekuensil rate, flow, dan volume pernapasan.

Sehubungan dengan temuan pada penelitian ini, beberapa faktor dianggap sebagai batasan penelitian ini, diantaranya: belum dipertimbangkannya determinan karakteristik populasi khusus seperti tingkat melek huruf, dan gangguan kognitif keterbatasan lain dari penelitian ini terkait dengan heterogenitas penelitian, sampel, dan berbagai skala yang dapat membatasi relevansi umum dari temuan kami. Populasi sampel yang dipilih untuk penelitian ini ditetapkan hanya mencakup pasien pasca operasi dalam keadaan istirahat, sehingga tidak ada pertimbangan 
yang diberikan untuk nyeri pada kondisi fluktuasi tinggi yang sering terlihat ketika pasien bergerak atau batuk setelah operasi. Karena penelitian ini tidak bermaksud untuk mengamati tingkat rasa nyeri pada kondisi yang berbeda, melainkan bagaimana cara menilai untuk menemukan bentuk/metode yang mudah dipahami atau yang nyaman bagi subyek penelitian. Pada akhirnya, hasil penelitian ini menunjukkan bahwa NRS, WBFS atau $V A S$ semuanya dapat digunakan dengan baik. Pada hakikatnya yang paling penting, adalah yang menjadi fokus pilihan bukanlah jenis skala, tetapi pilihan penggunaan sesuai kondisi klinis dan latar belakang pasien terkait. Seperti, tingkat pendidikan pasien.

\section{KESIMPULAN}

Berdasarkan hasil penelitian dapat disimpulkan bahwa Interpretasi skala nyeri dari subyek penelitian menggunakan skala Lickert terkait skala $\operatorname{VAS}(13,62)$, lebih rendah daripada skala NRS $(17,14)$ dan $W B F S(21,33)$. NRS, WBFS atau VAS semuanya bekerja dengan baik dalam mengukur nyeri. WBFS memiliki nilai interpretasi skala yang paling baik.

\section{SARAN}

Perlu diteliti lebih lanjut, terkait tingkat pemahaman petugas medis. Serta perlu dioptimalkan untuk menekan dan monitoring morbiditas terkait nyeri di RSUD Dr. Soetomo Surabaya.

\section{REFERENSI}

Alghadir, A. H., Anwer, S., Iqbal, A., \& Iqbal, Z. A. (2018). Test-retest reliability, validity, and minimum detectable change of visual analog, numerical rating, and verbal rating scales for measurement of osteoarthritic knee pain. Journal of Pain Research, 11, 851.

Ali, N., \& Lewis, M. (2015). Understanding pain: an introduction for patients and caregivers. Rowman \& Littlefield.

Alice, N. (2012). A cross sectional study of use of different pain assessment tools in Chinese cancer patients. Journal of Pain Management, 5(1), ,8391.

Angeline, M., Allan, C., Ana, H., \& Kenneth, T. (2015). Comparison of the different pain assessment scales used in adult patients seen at the Philippine General Hospital rheumatology out-patient clinic. Philippine Journal of Internal Medicine, 53(4), 1-5.

Avery, V. R. (2010). Comparing the visual analog scale and verbally administered numeric rating scale in traumatic versus non-traumatic pain in a community hospital emergency center.

Brennan, T. J. (2011). Pathophysiology of postoperative pain. Pain, $152(3$ Suppl), S33.

Chiang, H.-L., Huang, Y.-C., Lin, H.-S., Chan, M.-H., \& Chia, Y.-Y. (2019). Hypertension and Postoperative Pain: A Prospective Observational Study. Pain Research and Management, 2019.

Evans, M. R. (2012). Pathophysiology of Pain and Pain Assessment Module 1 Pain Management: Pathophysiology of Pain and Pain Assessment 
American Academy of Orthopaedic Surgeons. American Medical Association, 7,1-12.

Fitzgerald, S., Tripp, H., \& HalksworthSmith, G. (2017). Assessment and management of acute pain in older people: barriers and facilitators to nursing practice. Australian Journal of Advanced Nursing, The, 35(1), 48.

Gallagher, E. J., Bijur, P. E., Latimer, C., \& Silver, W. (2002). Reliability and validity of a visual analog scale for acute abdominal pain in the ED. The American Journal of Emergency Medicine, 20(4), 287-290.

Glowacki， D. (2015). Effective pain management and improvements in patients' outcomes and satisfaction. Critical Care Nurse, 35(3), 33-41.

Hjermstad, M. J., Fayers, P. M., Haugen, D. F., Caraceni, A., Hanks, G. W., Loge, J. H., ... (EPCRC, E. P. C. R. C. (2011). Studies comparing Numerical Rating Scales, Verbal Rating Scales, and Visual Analogue Scales for assessment of pain intensity in adults: a systematic literature review. Journal of Pain and Symptom Management, 41(6), 10731093.

Jafari, H., Courtois, I., Van den Bergh, O., Vlaeyen, J. W. S., \& Van Diest, I. (2017). Pain and respiration: a systematic review. Pain, 158(6), 9951006.

Kjeldsen, H. B., Klausen, T. W., \& Rosenberg, J. (2016). Preferred presentation of the visual analog scale for measurement of postoperative pain. Pain Practice, 16(8), 980-984.

Kusuma Sari, T. (2016). Introduction of a neonatal pain and agitation protocol at neonatal intensive care unit. Dr Soetomo Hospital. Introd a neonatal pain Agit Protoc neonatal intensive care unit drSoetomo Hosp.

Magbagbeola, J. A. (2001). Pain assessment in Nigerians--visual analogue scale and verbal rating scale compared. West African Journal of Medicine, 20(3), 219-222.

Merskey, H., \& Bogduk, N. (1994). IASP Task Force on Taxonomy. Classification of chronic pain. Seattle: IASP press.

Naghibi, K., Saryazdi, H., Kashefi, P., \& Rohani, F. (2013). The comparison of spinal anesthesia with general anesthesia on the postoperative pain scores and analgesic requirements after elective lower abdominal surgery: A randomized, doubleblinded study. Journal of Research in Medical Sciences: The Official Journal of Isfahan University of Medical Sciences, 18(7), 543.

Schroeder, D. L., Hoffman, L. A., Fioravanti, M., Medley, D. P., Zullo, T. G., \& Tuite, P. K. (2016). Enhancing nurses' pain assessment to improve patient satisfaction. Orthopaedic Nursing, 35(2), 108-117.

Taylor, L. J., \& Herr, K. (2003). Pain intensity assessment: a comparison of selected pain intensity scales for use in cognitively intact and cognitively impaired African American older adults. Pain Management Nursing, 4(2), 87-95.

Thong, I. S. K., Jensen, M. P., Miró, J., \& Tan, G. (2018). The validity of pain intensity measures: what do the NRS, VAS, VRS, and FPS-R measure? Scandinavian Journal of Pain, 18(1), 99107.

Treede, R.-D. (2018). The International Association for the Study of Pain definition of pain: as valid in 2018 as in 1979, but in need of regularly updated footnotes. Pain Reports, 3(2).

Von Korff, M., Jensen, M. P., \& Karoly, P. (2000). Assessing global pain severity by self-report in clinical and health services research. Spine, 25(24), 3140-3151.

Wall\&Melzack's.

(n.d.).

TEXTBOOKOFPAIN. (I. M.

StephenB.McMahon, Ed.). 
Care: Jurnal Ilmiah Ilmu Kesehatan Vol.8, No.3, 2020, hal 447-463

Philadelphia: Elsevier Saunders, Inc.

Wels D. (2015). Management of postoperative pain. Anaesth Suppl
ManagPostoper pain Manag

[Internet]. 